\begin{tabular}{c|c|c}
\hline $\begin{array}{c}\text { JURNALPENELITIAN KEPERAWATAN } \\
\text { MEDIK }\end{array}$ & VOL. 1 NO. 2 & $\begin{array}{c}\text { EDITION: NOVEMBER 2018 - } \\
\text { APRIL 2019 }\end{array}$ \\
\hline & http://ejournal.delihusada.ac.id/index.php/JPKM & \\
\cline { 2 - 2 } RECEIVED: 6 FEBRUARI 2019 & ACCEPTED: 24 APRIL 2019 \\
\hline
\end{tabular}

\title{
HUBUNGAN KUALITAS PELAYANAN KESEHATAN TERHADAP TINGKAT KEPUASAN PASIEN PESERTA BPJS MANDIRI DI PUSKESMAS DELITUA KABUPATEN DELI SERDANG TAHUN 2018
}

\author{
Selamat Ginting ${ }^{1}$, Adi Arianto ${ }^{2}$ \\ Institut Kesehatan Deli Husada Deli Tua, JL. Besar Deli Tua, No, 77 Kecamatan Deli Tua \\ Email : selamatginting18@gmail.com
}

\begin{abstract}
Health is a prosperous state of the body, soul, and social which is very possible for every individual to live productively in a social and economic way. Tests of research are to identify the relationship between the quality of health services to the level of satisfaction of BPJS Mandiri in Public Health Center Deli Tua Kab Deli Serdang. The research method uses an analytical survey type with a sample of 95 people. The results of the study are that there is a significant relationship between Tangible, reliability, responsiveness, assurance, empathy for the satisfaction of BPJS Mandiri in Public Health Center Deli Tua $K a b$ Deli Serdang wit p-value(0.00). The conclusion in this study is that the most dominant factors affecting patient satisfaction are direct evidence of this indicated by the highest $\operatorname{Exp}(B)$ of 6,374
\end{abstract}

Keywords: quality of health services, satisfaction patient's, BPJS

\section{PENDAhUlUAN}

Kesehatan merupakan keadaan sejahtera dari tubuh, jiwa, serta sosial yang sangat mungkin setiap individu hidup produktif dengan cara sosial serta ekonomis. Dengan kesehatan ini setiap individu dapat melaksanakan aktivitas sebagai makhluk ciptaan Tuhan Yang Maha Esa sehingga dapat hidup produktif baik secara sosial maupun ekonomis (Wijoyo, 2006).

Dalam Sistem Kesehatan Nasional Tahun 2012, Puskesmas adalah sebagai fasilitas pelayanan kesehatan tingkat pertama dengan mempunyai 3 fungsi, yakni sebagai berikut: pusat penggerak pembangunan berwawasan kesehatan, pusat pelayanan kesehatan tingkat pertama dan pusat pemberdayaan Masyarakat dan Keluarga Puskesmas dalam menyelenggarakan upaya kesehatan masyarakat tingkat pertama dan upaya kesehatan perorangan tingkat pertama dilakukan secara berkesinambungan dan terintegrasi.
Berbagai permasalahan yang muncul di media massa dan yang ditemui di Puskesmas Deli Tua Kabupaten Deli Serdang, dapat penulis rangkum sebagai berikut; banyaknya pasien yang harus dilayani di Provider Pertama (PPK 1) menyebabkan antrian menjadi lebih panjang, pemeriksaan dilakukan dengan cepat dan terkesan tergesa-gesa sehingga pasien merasa tidak cukup waktu untuk berkonsultasi dengan dokter. Selain itu, Pemberian obat yang dibatasi membuat pasien tidak nyaman, karena peserta BPJS Kesehatan harus bolakbalik mengantri untuk berobat lagi.

Pemahaman yang baik tentang kepuasan pasien merupakan salah satu hal penting yang dapat digunakan sebagai masukan dalam menentukan kebijakan dan pengambilan keputusan dalam upaya peningkatan mutu dan kualitas pelayanan Puskesmas khususnya Puskesmas Deli Tua Kabupaten Deli Serdang. 


\begin{tabular}{c|c|c}
\hline $\begin{array}{c}\text { JURNALPENELITIAN KEPERAWATAN } \\
\text { MEDIK }\end{array}$ & VOL. 1 NO. 2 & $\begin{array}{c}\text { EDITION: NOVEMBER 2018 - } \\
\text { APRIL 2019 }\end{array}$ \\
\cline { 1 - 2 } & http://ejournal.delihusada.ac.id/index.php/JPKM & \\
\cline { 2 - 3 } RECEIVED: 6 FEBRUARI 2019 & ACCEPTED: 24 APRIL 2019 \\
\hline
\end{tabular}

\section{METODE}

Jenis penelitian yang digunakan adalah survey analitik. Penelitian ini disusun sebagai penelitian induktif yaitu mencari dan mengumpulkan data yang ada dilapangan dengan tujuan untuk mengetahui faktorfaktor, unsur-unsur bentuk dan suatu sifat fenomena yang ditemukan. Populasi dalam penelitian ini adalah pasien pengguna BPJS yang berjumlah 95 orang. Teknik Sampel dalam penelitian ini menggunakan total sampling yaitu semua pasien pengguna BPJS mandiri dijadikan sampel sebanyak 95 orang.

\section{HASIL DAN PEMBAHASAN}

\section{Analisis Univariat}

Karakteristik responden dalam penelitian ini meliputi umur, jenis kelamin pendidikan, dan pekerjaan. Distribusi responden menurut karakteristik dapat dilihat pada tabel berikut

Tabel 1. Karakteristik Responden Di Puskesmas Deli Tua Deli Serdang

\begin{tabular}{|c|c|c|c|}
\hline \multirow[t]{2}{*}{ No } & \multirow[t]{2}{*}{ Identitas } & \multicolumn{2}{|c|}{ Kel. Intervensi } \\
\hline & & $\mathbf{N}$ & $\%$ \\
\hline \multirow[t]{7}{*}{1} & Umur & & \\
\hline & $<20$ tahun & 4 & 4.2 \\
\hline & 20-30 tahun & 9 & 9.5 \\
\hline & $31-40$ tahun & 34 & 35.8 \\
\hline & 41-50 tahun & 42 & 44.2 \\
\hline & $>50$ tahun & 6 & 6.3 \\
\hline & Jumlah & 95 & 100 \\
\hline \multirow[t]{4}{*}{2} & Jenis Kelamin & & \\
\hline & SD & 42 & 45.3 \\
\hline & SMP & 52 & 54.7 \\
\hline & Jumlah & 16 & 100 \\
\hline \multirow[t]{4}{*}{3} & Pendidikan & & \\
\hline & SMP & 2 & 12 \\
\hline & SMA & 4 & 25 \\
\hline & Jumlah & 16 & 100 \\
\hline \multirow[t]{9}{*}{4} & Pekerjaan & & \\
\hline & Mahasiswa & 1 & 1.1 \\
\hline & Siswa & 4 & 4.2 \\
\hline & IRT & 14 & 14.7 \\
\hline & Petani & 6 & 6.3 \\
\hline & Pedagang & 15 & 15.8 \\
\hline & Peg.Swasta & 20 & 21.1 \\
\hline & Wiraswasta & 35 & 36.8 \\
\hline & Jumlah & 16 & 100 \\
\hline
\end{tabular}

Karakteristik responden berdasarkan data demografi Umur pada kelompok mayoritas responden berumur antara 41-50 tahun yakni sebanyak 42 orang $(44.2 \%)$ dan minoritas berumur dibawah 20 tahun sebanyak 4 orang (4.2\%), mayoritas responden berjenis kelamin laki-laki sebnyak 52 orang $(54,7 \%)$ dan minoritas berjenis kelamin perepuan sebanyak perempuasn senyak 52 orang ( 54,7\%). Mayoritas responden berpendidikan Sekolah Menengah Atas (SMA) sebanyak 44 orang ( $46,3 \%$ ) dan minoritas berpendidikan SI sebanyak 3 orang (3.2\%) dan mayoritas responden bekerja sebagai wiraswasta sebanyak 35 orang (36.8\%) dan minoritas responden bekerja sebagai mahasiswa sebanyak 1 orang (1.1\%).

Tabel 2. Karakteristik resonden berdasarkan variabel

\begin{tabular}{lcc}
\hline \multicolumn{1}{c}{ Variabel } & Frek. & (\%) \\
\hline Bukti Langsung & & \\
Baik & 50 & 52.6 \\
Kurang & 45 & 47.4 \\
Kehandalan & & \\
Baik & 55 & 57.9 \\
Kurang & 40 & 42.1 \\
Daya Tanggap & & \\
Baik & 49 & 51.6 \\
Kurang & 46 & 48.4 \\
Jaminan & & \\
Baik & 48 & 50.5 \\
Kurang & 47 & 45.5 \\
Empati & & \\
Baik & 54 & 56.8 \\
Kurang & 41 & 43.2 \\
Kepuasan & & \\
Puas & 51 & 53.7 \\
Kurang & 44 & 46.3 \\
\hline
\end{tabular}

Berdasarkan Tabel 2 diatas diketahui bahwa mayoritas responden yang menyatakan bukti langsung baik sebanyak 50 orang $(52,6 \%)$, mayoritas responden yang menyatakan kehandalan baik sebanyak 55 orang $(57,9 \%)$. Mayoritas responden yang menyatakan daya tanggap baik seabnyak 48 orang $(50,5 \%)$. 


\begin{tabular}{|c|c|c|}
\hline $\begin{array}{l}\text { JURNALPENELITIAN KEPERAWATAN } \\
\text { MEDIK }\end{array}$ & VOL. 1 NO. 2 & $\begin{array}{l}\text { EDITION: NOVEMBER } 2018- \\
\text { APRIL } 2019\end{array}$ \\
\hline & http://ejournal.delihusada.ac.id/index.php/JPKM & \\
\hline RECEIVED: 6 FEBRUARI 2019 & REVISED: 21 MARET 2019 & ACCEPTED: 24 APRIL 2019 \\
\hline
\end{tabular}

Mayoritas responden yang menyatakan jaminan baik sebanyak 48 orang (50.5\%). Mayoritas responden yang menyatakan empati sebanyak 54 orng (56.8\%)

\section{Analisis Bivariat}

Tabel 3. Tabulasi Silang Antara Variabel

\begin{tabular}{|c|c|c|c|c|c|c|c|}
\hline \multirow{3}{*}{$\begin{array}{l}\text { Variabel } \\
\text { Indevende } \\
\text { n }\end{array}$} & \multicolumn{6}{|c|}{ Kepuasan Pasien } & \multirow{2}{*}{$\begin{array}{c}\text { P } \\
\text { Val } \\
\text { ue } \\
\end{array}$} \\
\hline & \multicolumn{2}{|c|}{ Puas } & \multicolumn{2}{|c|}{ Kurang } & \multicolumn{2}{|c|}{ Total } & \\
\hline & $\mathrm{N}$ & $\%$ & $\mathrm{n}$ & $\%$ & $n$ & $\%$ & \\
\hline \multirow{2}{*}{\multicolumn{8}{|c|}{$\begin{array}{l}\text { Bukti } \\
\text { Langsung }\end{array}$}} \\
\hline & & & & & & & \\
\hline Baik & 41 & 82.0 & 9 & 18.0 & 50 & 100 & \\
\hline Kurang & 10 & 22.2 & 35 & 77.8 & 45 & 100 & \\
\hline \multicolumn{8}{|l|}{$\begin{array}{l}\text { Kehandala } \\
\text { n }\end{array}$} \\
\hline Baik & 42 & 76.4 & 13 & 23.6 & 55 & 100 & \\
\hline Kurang & 9 & 22.5 & 31 & 77.5 & 40 & 100 & \\
\hline \multicolumn{8}{|l|}{ Daya } \\
\hline \multicolumn{8}{|l|}{ Tanggap } \\
\hline Baik & 39 & 79.6 & 10 & 20.4 & 49 & 100 & 0.00 \\
\hline Kurang & 12 & 26.1 & 34 & 73.9 & 46 & 100 & \\
\hline \multicolumn{8}{|l|}{ Jaminan } \\
\hline Baik & 36 & 75.9 & 12 & 25.0 & 48 & 100 & \\
\hline Kurang & 15 & 31.9 & 32 & 68.1 & 47 & 100 & \\
\hline \multicolumn{8}{|l|}{ Empati } \\
\hline Baik & 40 & 74.1 & 14 & 25.9 & 54 & 100 & \\
\hline Kurang & 11 & 26.8 & 30 & 73.2 & 41 & 100 & \\
\hline
\end{tabular}

Berdasarkan Tabel 3 diatas dapat diketahui bahwa mayoritas responden yang puas dengan pelayanan kesehatan puskesmas yang menyatakan bukti langsung adalah baik sebanyak 41 orang (82.0\%). mayoritas responden yang puas dengan kualitas pelayanan puskesmas adalah yang menyatakan kehandalan adalah baik yakni sebanyak 42 orang (76.4\%). mayoritas responden yang puas dengan kualitas pelayanan puskesmas adalah yang menyatakan daya tanggap adalah baik yakni sebanyak 39 orang (79.6\%) mayoritas responden yang puas dengan kualitas pelayanan puskesmas adalah yang menyatakan jaminan adalah baik yakni sebanyak 36 orang $(75.0 \%)$ mayoritas responden yang puas dengan kualitas pelayanan puskesmas adalah yang menyatakan empati adalah baik yakni sebanyak 40 orang $(74.1 \%)$

\section{Pembahasan}

Bukti fisik mencakup sarana dan prasarana. Menurut Yandianto (2000) sarana adalah sesuatu yang dipakai sebagai alat dalam mencapai maksud dan tujuan. Sarana merupakan aset sebuah organisasi dalam rangka pencapaian tujuan. Dengan adanya sarana yang lengkap, maka tenaga kesehatan akan mudah untuk melaksanakan tugas dan fungsinya sebagai pemberi pelayanan kesehatan (Sedarmayanti, 2001).

Hasil uji chi-square memperlihatkan bahwa pada nilai contingency correction $t_{\text {hitung }}=$ 31.676 dan $p$-value $=0.000$, lebih kecil dari 0.05 , sehingga dapat disimpulkan bahwa bukti langsung memiliki hubungan signifikan dengan kepuasan pasien. . Hasil penelitian ini sejalan dengan penelitian Ritna Rahmawati, Program MM Universitas Muhammadiah Surakarta, 2014, berjudul Pengaruh Kualitas Pelayanan Terhadap Kepuasan Pasien Pengguna BPJS dan hasil penelitian membuktikan bahwa kualitas pelayanan yang baik memberi pengaruh terhadap peningkatan kepuasan pasien untuk datang berobat $(p<0.05)$.

Parasuraman (2006), memberikan pengertian kehandalan adalah salah satu dimensi dari pelayanan berkualitas. Pelayanan berkualitas merupakan upaya yang dilakukan oleh perusahaan untuk memenuhi harapan pelanggannya. Kinerja harus sesuai dengan harapan pelanggan yang berarti ketepatan waktu, pelayanan yang sama untuk semua pelanggan tanpa kesalahan, sikap yang simpatik, dan dengan akurasi yang tinggi.

Hasil uji chi-square memperlihatkan bahwa nilai contingency correction $t_{\text {hitung }}=24.899$ dan $p$-value $=0.000$, lebih kecil dari 0.05, sehingga dapat disimpulkan bahwa kehandalan memiliki hubungan signifikan dengan kepuasan pasien.

Berdasarkan hasil penelitian dan teori terkait tersebut di atas, dapat disimpulkan bahwa kemampuan medis para petugas kesehatan Puskesmas Deli Tua Kabupaten Deli Serdangpada umumnya sudah baik meskipun 


\begin{tabular}{|c|c|c|}
\hline $\begin{array}{l}\text { JURNALPENELITIAN KEPERAWATAN } \\
\text { MEDIK }\end{array}$ & VOL. 1 NO. 2 & $\begin{array}{l}\text { EDITION: NOVEMBER } 2018- \\
\text { APRIL } 2019\end{array}$ \\
\hline & http://ejournal.delihusada.ac.id/index.php/JPKM & \\
\hline RECEIVED: 6 FEBRUARI 2019 & REVISED: 21 MARET 2019 & ACCEPTED: 24 APRIL 2019 \\
\hline
\end{tabular}

sebagian besar masih ada yang kurang baik terutama dalam pemeriksaan pasien terkadang dilakukan oleh Bidan atau perawat apabila dokter sedang tidak berada ditempat,sehingga kurang mendukung kepuasan pasien.

Menurut teori, daya tanggap mempunyai pengaruh positif terhadap kepuasan konsumen. Semakin baik persepsi konsumen terhadap daya tanggap perusahaan maka kepuasan konsumen juga akan semakin tinggi demikian pula sebaliknya. Hal ini sesuai dengan pendapat yang mengatakan bahwa daya tanggap (responsiveness) yaitu suatu kebijakan untuk membantu dan memberikan pelayanan yang cepat (responsif) dan tepat kepada pelanggan, dengan penyampaian informasi yang jelas (Parasuraman dkk, 1998; lupiyoadi \& Hamdani, 2006).

Hasil uji chi-square memperlihatkan bahwa nilai contingency correction $t_{\text {hitung }}=25.208$ dan $p$-value $=0.000$, lebih kecil dari 0.05 , sehingga dapat disimpulkan bahwa daya tanggap memiliki hubungan signifikan dengan kepuasan pasien.

Berdasarkan hasil penelitian dan teori terkait tersebut di atas, dapat disimpulkan bahwa daya tanggap petugas kesehatan Puskesmas Deli Tua Kabupaten Deli Serdang pada umumnya sudah baik meskipun masih banyak kelemahan dimana daya tanggap ini adalah suatu kebijakan untuk membantu dan memberikan pelayanan yang cepat (responsif) dan tepat sehingga dapat memberi kepuasan bagi pasien dalam berobat.

Menurut teori Kotler (2001) bahwa jaminan (assurance) adalah pengetahuan terhadap produk secara tepat, kesopansantunan karyawan dalam memberi pelayanan, kemampuan dalam menanamkan kepercayaan dan keyakinan pelanggan terhadap perusahaan. Jaminan mencakup kemampuan pengetahuan dan kesopanan karyawan serta kemampuan mereka untuk menimbulkan kepercayaan dan keyakinan sehingga bebas dari bahaya, resiko, ataupun keraguan.

Hasil uji chi-square memperlihatkan bahwa nilai contingency correction $t_{\text {hitung }}=16.039$ dan $p$-value $=0.000$, lebih kecil dari 0.05, sehingga dapat disimpulkan bahwa jaminan memiliki hubungan signifikan dengan kepuasan pasien.

Berdasarkan hasil penelitian dan teori terkait tersebut di atas, dapat disimpulkan bahwa adanya jaminan pelayanan dan perawatan medis yang baik memberi kepuasan tersendiri bagi pasien. Dengan kata lain, semakin terjamin pelayanan kesehatan, semakin tinggi kepuasan pasien.

Menurut teori Parasuraman. dalam Lupiyoadi dan Hamdani (2006), empati (emphaty) yaitu perhatian dengan memberikan sikap yang tulus dan berifat individual atau pribadi yang diberikan perusahaan kepada pelanggan, kemampuan karyawan untuk berkomunikasi dengan pelanggan. Semakin baik persepsi konsumen terhadap kepedulian yang diberikan oleh perusahaan maka kepuasan konsumen juga akan semakin tinggi demikian juga sebaliknya.

Hasil uji chi-square memperlihatkan bahwa nilai contingency correction $t_{\text {hitung }}=19.064$ dan $p$-value $=0.000$, lebih kecil dari 0.05 , sehingga dapat disimpulkan bahwa empati memiliki hubungan signifikan dengan kepuasan pasien.

\section{KESIMPULAN}

Berdasarkan hasil penelitian dan analisis data tentang faktor-faktor yang mempengaruhi kepuasan pasien di Puskesmas Deli Tua 


\begin{tabular}{|c|c|c|}
\hline $\begin{array}{l}\text { JURNALPENELITIAN KEPERAWATAN } \\
\text { MEDIK }\end{array}$ & VOL. 1 NO. 2 & $\begin{array}{l}\text { EDITION: NOVEMBER } 2018- \\
\text { APRIL } 2019\end{array}$ \\
\hline & http://ejournal.delihusada.ac.id/index.php/JPKM & \\
\hline RECEIVED: 6 FEBRUARI 2019 & REVISED: 21 MARET 2019 & ACCEPTED: 24 APRIL 2019 \\
\hline
\end{tabular}

Kabupaten Deli Serdang Tahun 2018 , dapat disimpulkan bahwa:

1. Bukti langsung memiliki hubungan dan pengaruh signifikan terhadap kepuasan pasien. Dengan kata lain, semakin baik bukti langsung, semakin tinggi pula kepuasan pasien.

2. Kehandalan memiliki hubungan dan pengaruh signifikan terhadap kepuasan pasien. Dengan kata lain, semakin baik kehandalan, semakin tinggi pula kepuasan pasien.

3. Daya tanggap memiliki hubungan dan pengaruh signifikan terhadap kepuasan pasien. Dengan kata lain, semakin baik daya tanggap, semakin tinggi pula kepuasan pasien.

4. Jaminan memiliki hubungan dan pengaruh signifikan terhadap kepuasan pasien. Dengan kata lain, semakin baik jaminan, semakin tinggi pula kepuasan pasien.

5. Empati memiliki hubungan dan pengaruh signifikan terhadap kepuasan pasien. Dengan kata lain, semakin baik empati, semakin tinggi pula kepuasan pasien.

6. Faktor yang paling dominan mempengaruhi kepuasan pasien adalah bukti langsung. Hal ini diindikasikan oleh nilai Exp (B) tertinggi yakni sebesar 6.374

\section{DAFTAR PUSTAKA}

Abiyazha. 2013. Istilah - istilah Dalam Statistic Rumah Sakit. Jogjakarta: Nuha Medika

Agusnar, 2012 Pengaruh Tarif dan Fasilitas Terhadap Kepuasaan Pasien di Rmah Sakit Tri Trogamba.

Alamsyah, D., 2011. Manajemen Pelayanan Kesehatan. Yogyakarta: Nuha Medika.

Arikunto, S., 2010. Prosedur Penelitian. Edisi Revisi Cetakan 14. Jakarta: Rineka Cipta.
Azwar, A. 2008. Menjaga Kualitas pelayanan Kesehatan. Jakarta: Pustaka Sinar Harapan.

Asmuji, 2013.Manajeme Keperawatan.Ar.ruzz Media.Yogyakarta

Calisir, F, C.A Gumussory, A.E Bagrak tariogo and B.Kaya. Affets of Servise Quality Dimensions on Customer Statis[action and Return Intension in Different Hospital Types. Proceddings of the 2012 Internasional Gompference on Industria; Engineering and Operations Management,2012

Efendi; Sofian,. Tukiran. 2012. Metode Penelitian Survei. Edisi Revisi. Jakarta: LP3ES.

Fidella, Firwan Firdaus. 2015. Evaluasi Kualitas Pelayanan Terhadap Kepuasan Pasien Rawat Jalan Peserta BPJS di RSUD Penembahan Senapati Bantul< Magister Manajemen Rumah Sakit, Universitas Muhammadiyah, Yogyakarta.

Hidayat, A. Aziz Alimul. (2011). Metode Penelitian Kebidanan dan Teknik Analisa Data. Salemba Medika. Jakarta, pp, 117-125.

Hurriyati, R. 2005. Bauran Pemasaran dan Loyalitas Konsumen. Alfabetta. Bandung.

Lupiyoadi dan Hamdani, 2006. Manajemen Pemasaran jasa Edisi kedua. Penerbit Salemba Empat: Jakarta

Parasuraman, A \& Zeithamla, V.A 1990, "Quality Counts in Service Too", Business Horizons, Vol. 28 No. 3 , pp.44-46

Wibowo, 2011. Manajemen Kerja. Edisi ketiga, Jakarta: PT. Raja Grafindo Persada.

Wijoyo,D.2006,Manajemen Kualitas pelayanan Kesehatan Volume 1.

Surabaya:Airlanga University press.

Winarno, 2011, Manajemen Administrasi Rumah Sakit, Edisi II Jakarta: UIPres 